\title{
Surgery of Brain Metastases - Pro and Contra
}

\author{
G. Schackert \\ Department of Neurosurgery, Technical University of Dresden
}

Metastases to the brain occur in $20-30 \%$ of patients with systemic cancer. Depending on the primary tumor the frequency is even higher. In autopsy studies of patients with metastasizing malignant melanomas the occurrence of cerebral lesions ranges between 40 and $75 \%$. Most brain metastases, however, generate from primary lung and breast carcinomas.

The brain metastasis threatens the life of the patient by increasing the intracranial pressure or by seeding in functionally important brain areas.

Neurosurgical techniques have improved tremendously during the last two decades. One of the main advances was the development of neuronavigational devices. Neuronavigation is a computer-aided method that enables us to fuse 3D-images ('virtual world'), obtained preoperatively, with the physical world of the intraoperative situation. By this method it is possible to target deep-seated or multiple lesions by pre- and intraoperative computed imaging and by choosing the operative approach so as to avoid additional iatrogenic neurological deficits.

The further important progress is the intraoperative identification of functionally important areas of the brain, e.g. the motor cortex and the speech area by electrophysiological monitoring, called 'brain mapping'. Intraoperatively, the motor cortex can be defined by somato-sensory evoked potentials. The phase reversal of N20 is specific for the central sulcus. This method can be applied on a routine basis. Brain mapping of the speech area has to be performed on awake patients. Therefore, speech monitoring is only applied in specialized centers and, in general, is not necessary in patients with metastasis.

The advances in neurosurgical techniques have led to a new understanding in surgery of metastasis. The fact that cerebral lesions - even small and deep-situated ones - can be approached in a reliable and safe manner, makes surgery a valuable alternative in metastasis treatment.

The question arises, when is it reasonable to perform surgery in cerebral metastases and when should other methods be preferred?
It has to be kept in mind that cerebral metastases occur usually in the final stage of the metastasizing process. Therefore, in general the survival time will be limited. Several prognostic factors have been defined, which mainly influence the survival time of the patients:

- the extent of extracerebral metastases,

- the number of cerebral lesions,

- the time interval between the occurrence of the primary tumor and the development of cerebral metastases,

- the Karnofsky performance score, and

- the age of the patient [1].

The indication for surgery is based on these prognostic factors.

Surgery is indicated in patients with a solitary brain metastasis, which means that the primary tumor is under control and the patient is free of extracerebral metastasis. Whenever the cerebral lesion is accessible, surgery should be performed [2, 3]. In these cases even long-term survivors can be expected (more than 10 years). However, the size, the location, and the histology of the metastasis will determine the decision pro and contra surgery.

For instance: Small-cell lung cancer is known to be very radioand chemosensitive. In these cases radio- or chemotherapy will be adequate. These lesions should not be operated on, with the exception of very big tumors, which have led to lifethreatening increase in brain pressure. Also lesions with a diameter of $1 \mathrm{~cm}$ or less or metastases localized in the brain stem or basal ganglia are favorably treated by radiosurgery. In all other cases we prefer surgery whenever the patient is in good clinical condition and under the age of 70 (up to maximally 75) years.

In singular cerebral metastasis the extent of the extracerebral seeding, the control of the primary tumor, the Karnofsky performance score, and the age of the patient will determine the decision pro or contra operation. Stable disease, a Karnofsky score of more than 70 , and age under 70 years will favor surgery. Numerous retrospective studies $[2,3]$ could demon-

\begin{tabular}{ll}
\hline KARGER & ( ) 2002 S. Karger GmbH, Freiburg \\
$\begin{array}{l}\text { Fax +49 7614520714 } \\
\begin{array}{l}\text { E-mail Information@Karger.de } \\
\text { www.karger.com }\end{array}\end{array}$ & $\begin{array}{c}\text { Accessible online at: } \\
\text { www.karger.com/journals/onk }\end{array}$ \\
&
\end{tabular}

Prof. Dr. Gabriele Schackert

Universitätsklinikum Carl Gustav Carus

Fletscherstr. 74

D-01307 Dresden (Germany)

Tel. + 49351 458-2883, Fax -4304 
strate that surgery plus radiotherapy is superior to radiotherapy alone. In a prospective randomized trial by Patchell et al. 1990 [4] it could be shown that patients receiving surgery plus radiotherapy lived significantly longer than those who were treated by radiotherapy alone. The median survival time of patients treated with radiotherapy ranges between 3 and 6 months, whereas patients treated with surgery and radiotherapy have a median survival time of about 9-12 months. To date it is not clear whether radiotherapy has to follow after complete removal of a cerebral metastasis. In 1998, Patchell et al. [5] published a prospective randomized trial comparing surgery versus surgery plus radiotherapy in single brain metastasis. The investigators found out that the survival time of the patients did not differ between both groups; but they also noticed that recurrent tumor growth was significantly reduced in patients who were irradiated in addition to surgery. It has to be demanded that patients who have undergone an operation should be followed by early postoperative magnetic resonance imaging (MRI), in order to determine whether complete tumor removal could be achieved.

The common treatment of multiple brain metastases is conventional radiotherapy. Since the advances in neurosurgical techniques and the establishment of radiosurgery, multiple brain metastases can be approached by surgery or radiosurgery in addition to radiotherapy [6]. As described above, multiple and deep-seated lesions can be targeted by neuronavigation. Number and size of the tumors are of importance for targeted therapies. It has been defined that 3 metastatic lesions with a diameter of $3 \mathrm{~cm}$ or less can be treated by radiosurgery. Also 3 or maximally 4 lesions can be extirpated by surgery. In case of surgery, however, the lesions may be larger than $3 \mathrm{~cm}$. Especially if one of the tumors is of large size and causes elevated brain pressure, surgical extirpation is indicated. Retrospective studies [7-9] evaluating surgical extirpation of multiple brain metastases could show that the median survival time of the patients averages about 1 year and, therefore, seems to be almost the same as in patients with single brain metastasis.

It is always a difficult decision whether patients with multiple lesions should be operated or not. Reasons for surgery are a
Karnofsky score of more than 70, age under 70 years, and a stable extracranial disease. Of course, the accessibility of the lesions is also a determining factor. Surgery should be applied when neurological deficits can be avoided or can be diminished by extirpating the large lesion. Surgery is not indicated if the patient has progressive disease and is in a reduced clinical condition. In these cases it has to be considered whether radiosurgery might be adequate or radiotherapy only might be the appropriate treatment. But considering radiosurgery as adequate treatment, the indication does not differ greatly from that for surgery except for the size and site of the tumor, as mentioned above [6].

The last question concerns the treatment of patients with recurrent brain metastases. Surgery is indicated if the time interval amounts to at least 4 months, the extracerebral metastases are stable, and the Karnofsky score is about 70. Bindal et al. [10] could demonstrate that even after surgical extirpation of recurrent brain metastases the median survival time may average about 11 months.

\section{Conclusion}

Surgery should be considered whenever possible. This means that the patient has to be in good clinical condition (Karnofsky performance score $>70$ ), the extracerebral metastases should be stable, the number of cerebral lesions should not exceed more than 3 seedings, and the age of the patient should be below 70 years. Since brain metastases are usually well circumscribed, complete extirpation seems to be possible. Postoperative MRI should be demanded in order to confirm complete extirpation. Additional radiotherapy is indicated in case of subtotal resection of a single lesion and in multiple lesions. In single brain metastasis a prospective randomized trial is necessary to prove whether conventional radiotherapy is essential after surgery in the primary treatment of the tumors or can be delayed until cerebral lesions recur. Radiosurgery is an alternative to surgery in the treatment of metastasis.

\section{References}

1 Lagerwaard FJ, Levendag PC, Nowak PJ, Eijkenboom WM, Hansens PE, Schmitz PI: Identification of prognostic factors in patients with brain metastases. A review of 1,292 patients. Int J Radiat Oncol Biol Phys 1999;43:795-803.

2 Nussbaum ES, Djalilian HR, Cho KH, Hall WA: Brain metastases. Histology, multiplicity, surgery, and survival. Cancer 1996;78:1781-1788.

3 Schackert G, Sobottka SB, Steinmetz A, Kirsch M: Current treatment strategies in brain metastases. Onkologie 2000;23:98-104.

4 Patchell RA, Tibbs PA, Walsh JM, Dempsey RJ, Maruyama Y, Kryscio RJ, Markesbery WR, Mcdonald JS, Young B: A randomized trial of surgery in the treatment of single metastases to the brain. $\mathrm{N}$ Engl J Med 1990;322:494-500.
5 Patchell RA, Tibbs PA, Regine WF, Dempsey RJ, Mohiuddin M, Kryscio RJ, Markesbery WR, Foon KA, Young B: Postoperative radiotherapy in the treatment of single metastases to the brain: A randomized trial. JAMA 1998;280:1485-1489.

6 Sanghavi SN, Miranpuri SS, Chappell R, Buatto JM, Sneed PK, Suh JH, Regine WF, Weltman E, King VJ, Goetsch SJ, Breneman JC, Sperduto PW, Scott C, Mabanta S, Mehta MP: Radiosurgery for patients with brain metastases: A multi-institutional analysis, stratified by the RTOG recursive partitioning analysis method. Int J Radiat Oncol Biol Phys 2001;51:426-434.

7 Sampson JH, Carter JH, Friedman AH, Seigler HF: Demographics, prognosis, and therapy in 702 patients with brain metastases from malignant melanoma. J Neurosurg 1998;88:11-20.
8 Bindal RK, Sawaya R, Leavens ME, Lee JJ: Surgical treatment of multiple brain metastases. J Neurosurg 1993;79:210-216.

9 Schackert G, Steinmetz A, Meier U, Sobottka SB: Surgical management of single and multiple brain metastases: Results of a retrospective study. Onkologie 2001;24:246-255.

10 Bindal RK, Sawaya R, Leavens ME, Hess KR, Taylor SH: Reoperation for recurrent metastatic brain tumors. J Neurosurg 1995;83:600-604. 